\title{
Action Mechanisms of Plant Growth Promoting Cyanobacteria in Crops In Situ: A Systematic Review of Literature
}

\author{
Luisa María Múnera-Porras, Santiago García-Londoño, \\ and Leonardo Alberto Ríos-Osorio
}

Research Group on Health and Sustainability, School of Microbiology, University of Antioquia, Calle 67 No. 53-108, Building 5, Office 135, Medellin 050010, Colombia

Correspondence should be addressed to Leonardo Alberto Ríos-Osorio; leonardo.rios@udea.edu.co

Received 26 February 2020; Revised 24 July 2020; Accepted 4 August 2020; Published 27 August 2020

Academic Editor: Isabel Marques

Copyright (C) 2020 Luisa María Múnera-Porras et al. This is an open access article distributed under the Creative Commons Attribution License, which permits unrestricted use, distribution, and reproduction in any medium, provided the original work is properly cited.

\begin{abstract}
Background and Aims. An excessive and prolonged use of fertilizers undermines soils' quality and, consequently, that of the crops they support, thus reducing the content of organic matter and generating environmental damages and problems to human health. Therefore, the use of biofertilizers such as cyanobacteria becomes a promising alternative. However, it is not always possible to generalize these fertilizers' applicability, because microorganisms may be impacted by the physical and chemical variations of their environment. We will describe the action mechanisms or the characteristics of cyanobacteria involved in plant growth promotion for different crops in situ through a systematic review of scientific literature. Methods. A comprehensive search for original articles in two different databases, ScienceDirect and Scopus, was performed. We included in our search documents published from 2009 to 2018. After the screening process and the addition of gray literature publications, we obtained 23 articles for theoretical analysis. Results. The studies were distributed mainly in Asia and part of Africa, without any important temporal variation. They also showed a tendency to describe the use of cyanobacteria genera such as Anabaena sp., Nostoc sp., and Calothrix sp., besides mechanisms as $\mathrm{N}_{2}$ fixation, phosphate solubilization, phytohormone production, bioactive compounds excretion, and symbiotic associations, mainly on rice, wheat and corn crops. Conclusions. Cyanobacteria fertilizers used in situ are a widespread strategy, mainly in cereal crops. Their use is predominant in countries where cereal crops make an important contribution to their national economy. The great variety of mechanisms and characteristics of cyanobacteria used to promote plant growth in the field demonstrate the dramatic influence that physical, chemical, and biological variables have in their development.
\end{abstract}

\section{Introduction}

Nowadays, agriculture represents one of the most significant causes of environmental contamination [1, 2]. The accelerated growth of the world's population demands greater food production. The World Health Organization (WHO) estimates that, by 2029, the world's food production will have to be increased by $50 \%$ [3]. The agricultural soil in the world is severely damaged by use of chemical fertilizers and excessive irrigation, which have led to erosion, nutrient depletion, and salinity. In Canada and the United States alone, around 3 billion tons of topsoil is lost due to the use of inorganic compounds on crops [4].
According to the Intergovernmental Panel on Climate Change (IPCC), agriculture causes $14 \%$ of the total greenhouse gas emissions produced by humans, about $47 \%$ and $58 \%$ of methane $\left(\mathrm{CH}_{4}\right)$ and nitrous oxide $\left(\mathrm{N}_{2} \mathrm{O}\right)$, respectively, where $\mathrm{N}_{2} \mathrm{O}$ emissions are directly related with nitrogen fertilizers [5]. Savci [1] claims that fertilizers are mainly of an inorganic nature and consist mostly of phosphate, nitrate, and ammonium; however, there are also organic fertilizers, which mainly consist of organic matter $[1,6,7]$. Inorganic fertilizers are considered a potential source of heavy metals such as mercury, cadmium, arsenic, lead, copper, and nickel, which are included on the Toxic and Priority Pollutant list of the United States Environmental 
Protection Agency (EPA) [8-10]. Some environmental problems caused by these compounds are soil fertility loss, inefficient nutrient-use, and low crop yields. Heavy metals and radioelements also accumulate, leading to the introduction of such compounds to the trophic chain and posing health hazards to living organisms [11-13].

All things considered, there is a need for other strategies that include compounds or aggregates other than conventional fertilizers in order to increase the crop yields without compromising the environment [14]. Biofertilizers, which consist of microbial inoculants such as bacteria and mycorrhizal fungi, have become the most promising option to increase nutrient availability in soils and plants, reduce dependence on expensive chemical fertilizers, and mitigate diseases related with crop handling, such as viroids, viruses, fungi, and pathogen bacteria [15-17]). Even when microbial inoculation has been adopted in several crop systems, their beneficial effects are difficult to reproduce, given their vulnerability to diverse types of environmental stress when exposed to conditions of drought, salinity, and extreme temperatures in the rhizosphere [18]. However, Swarnalakshmi et al. [19] indicate that the use of biofertilizers that contain consortiums of autochthonous microorganisms with promoting growth plant rhizobacteria (PGPR) can improve their effect [20].

Cyanobacteria are prokaryotic photoautotrophic microorganisms, and some are facultative heterotrophs, capable of using various sources of carbon and organic nitrogen, proliferating in all types of habitats, even if they are of extreme nature $[21,22]$. Both their physiological plasticity and their ability to fix nitrogen, which allows the inorganic nitrogen of the air $\left(\mathrm{N}_{2}\right)$ to be transformed into organic nitrogen to be used by plants, making them ideal for their use as biofertilizers. These bacteria can also form symbiotic associations with plants and other microorganisms; since they are photosynthetic, they are able to use carbon dioxide $\left(\mathrm{CO}_{2}\right)$ and water to generate monosaccharides and oxygen, from which plants can also benefit [22-24]. There is even more to using cyanobacteria as biofertilizers, since their action as PGPR or their PGP traits have also been proven through the observation of various mechanisms such as nutrient solubilization, plant growth hormone production, and, indirectly, antagonism to pathogenic fungi through siderophore production $[18,20,25]$. Also, they contain a wide variety of vitamins and produce a diversity of secondary metabolites that are a source of bioactive molecules, which also have herbicidal, insecticidal, and immunosuppressive activities. [3].

According to Wang et al. [22], several researchers have analyzed the use of cyanobacteria as biofertilizers in rice crops throughout countries such as India, Japan, the Philippines, and Iran. The diverse studies revealed an increase of up to $19.5 \%$ in rice crop yields. Increased grain yields, plant weights, and leaf lengths were also reported: a 53\% increase in the weight of rice plants, $66 \%$ in the length of roots, and $58 \%$ in the weight of leaves and stems [22]. In turn, the potential of cyanobacteria to increase nutrient bioavailability in other crops such as wheat, corn, beans, and cassava has been studied. However, field data on the plant promoting mechanisms of cyanobacteria are limited and disorganized. Additionally, there are no current review articles focused on describing such mechanisms, which means that the knowledge about the topic is still insufficient when considering subsequent implementation in experimental trials [20]. This is because the strong influence of external factors, especially in fluctuating environments, on the growth of cyanobacteria, also known as epigenetics, still constitutes a main problem $[26,27]$. Therefore, through a systematic review of scientific literature published in the last 10 years, the main objective of this study was to describe the action mechanisms of various cyanobacterial genera on plant growth promotion in diverse crop systems in situ.

\section{Materials and Methods}

2.1. Search Strategy. The study was carried out in accordance with the Prisma statement, it proposes a methodology for systematic reviews [28]. A systematic literature search was performed in ScienceDirect and Scopus databases under three criteria: (a) sensitivity, with DeCS and AGROVOC descriptors, (b) specificity, with the combination of Boolean operators and terms defined according to the research problem, and (c) completeness, by means of non-DeCS descriptors, together with the gray literature found.

The search was performed using the general route [(cyanobacteria) AND ("growth promoting" OR biofertilizer OR PGPR)]. In ScienceDirect and Scopus databases, the time limits "2009 to present" and "limit to 2009-2018," respectively, were used to cover the scientific literature published between these dates. Each specific route is presented below.

\subsection{ScienceDirect. ("Cyanobacteria”) AND ("growth pro-} moting” OR "biofertilizer" OR “PGPR”.)

\subsection{Scopus. ("Cyanobacteria") AND ("growth promoting" OR "biofertilizer" OR "PGPR".)}

In February 2018, the references found, together with the respective abstract, were registered in a Microsoft Office Excel database. Duplicates were eliminated.

2.4. Inclusion and Exclusion Criteria. The study included original research articles from the scientific literature of the last 10 years, written in English, which reported the action mechanisms of cyanobacteria on plant growth, types of crop used, and taxonomic classification of microorganisms involved in the mentioned process. The articles that described the use of ATCC strains and the performance of in vitro tests were excluded in order to analyze only the action of cyanobacteria as PGPR agents in natural and experimentally reproducible conditions. Data were extracted from each publication and tabulated for further analysis.

2.5. Reproducibility. The reproducibility of the study was assessed by using the search paths in the databases selected, together with the application of inclusion and exclusion criteria by two readers independently. Additionally, any 
discrepancy related with article eligibility was resolved by a third reader.

2.6. Analysis of Results. The data extracted and analyzed were related with the taxonomic classification of cyanobacteria, the mechanisms that intervene in plant growth promotion, and the respective cyanobacterial genera involved. The information gathered also referred to the type of crops where biofertilizers with cyanobacteria were employed.

\section{Results}

After using the search protocol indicated, a total of 127 articles were obtained (ScienceDirect 20 and Scopus 107). Once 17 duplicates were deleted at the Microsoft Excel database, 110 publications were evaluated based on their title and abstract content; 69 of them were discarded since they did not meet the inclusion criteria. A total of 41 articles were analyzed; 20 of them met the exclusion criteria. The search protocol resulted thus in a total of 21 articles selected for systematic review (Figure 1).

Two articles classified as a thesis or a dissertation were added by exhaustivity for a total of 23 papers obtained, in accordance with the same inclusion and exclusion criteria. This gray literature was found in Google Scholar (Table 1, Figure 1).

3.1. Distribution of Studies according to the Country of Origin and Publication Year. The systematic search of the scientific literature published between 2009 and 2018 resulted in a total of 23 articles, carried out in 5 different countries (Figure 2), among which India and Egypt stand out with 14 and 4 publications, respectively, followed by Iran and Pakistan with 2 publications each, and finally, Russia with 1 publication. The high number of publications in these countries is probably due to rice and wheat being cultivated in about 13.5 million hectares of the Indo-Gangetic Plain (IGP) in and around South Asia, in countries such as India, Pakistan, Bangladesh, and Nepal. These crops contribute to $80 \%$ of the total production of these cereals and are an important part of the economy and food sustainability across much of Asia [4].

Besides, the considerable number of paddy fields in these countries creates the necessary conditions for the proliferation and establishment of cyanobacteria [17]. On the other hand, regarding publication year, the works obtained in the systematic review did not show a significant variation and, in fact, maintained an average of approximately two articles per year between 2009 and 2018.

3.2. Research Objectives. Although all literature analyzed was determined by the inclusion and exclusion criteria established and is based on the same research premise, their diverse research objectives can be classified in four subgroups according to certain general features (Table 2). Simultaneously, the objectives can be divided into two groups. The first one contains those of an observational kind, which focus on understanding the effect of cyanobacteria used as PGPR and their mechanisms or their PGP traits. The second group, also the most predominant in the studies analyzed in this systematic review, contains the distinctly experimental objectives, which attempt to explain, through different methodologies, the phenomena involved in the mechanisms used by cyanobacteria.

\section{Discussion}

4.1. Cyanobacterial Genera Used as PGP. Cyanobacteria are photosynthetic prokaryotic organisms highly able to colonize many habitats under diverse environmental conditions and, therefore, are widely found around the world [33]. Cyanobacteria are used in agriculture as biofertilizers and soil stabilizers since they can promote cell division and plant elongation [41]. They can directly or indirectly increase plant growth rate: directly, through the production of biologically active growth promoting substances such as phytohormones (auxins, gibberellins, and cytokinins) and indirectly when cyanobacteria prevent the plant deterioration caused by one or more pathogenic microorganisms [33]. In addition, they can use other mechanisms such as $\mathrm{N}_{2}$ fixation and polysaccharide production [36]. Filamentous cyanobacteria Nostoc sp. and Anabaena sp. are some of the most commonly reported cyanobacteria genera with PGP characteristics. Other genera such as Cylindrospermum, Calothrix, Plectonema, Phormidium, and Gloeotrichia have also been mentioned $[4,25]$.

Nowadays, the genera most commonly used as PGPR in most crops are Nostoc sp. and Anabaena sp. $[4,17,18,34,43]$. However, genera such as Cylindrospermum sp., Synechococcus sp., Aulosira sp., Scytonema sp., Tolypothrix sp., Westiellopsis sp., Calothrix sp., Phormidium sp., and Oscillatoria sp. are also included in the reports (Figure 3) $[4,29,31,38]$. A study conducted by [20] reports the capacity of two cyanobacteria isolates, identified as Anabaena sp. and Calothrix sp., to produce ammoniacal and indole compounds and to inhibit the effects of a pathogenic fungus. It was established that the combination of these cyanobacterial isolates and Providencia sp. bacteria led to an enhanced yield in a wheat crop [25, 31]. In another study by [17], several Anabaena sp. species, including A. spiroides, A. variabilis, A. torulosa, and $A$. oscillarioides, were isolated and identified in paddy fields in Iran; a large proportion of these species was found in such soil during spring, therefore the season with the highest concentration of cyanobacteria population.

Discrepancies among the cyanobacterial species mentioned in studies may be attributed to their morphological or physiological differences, which include cell size and the presence of cell inclusions, such as gas vesicles and polyphosphate granules, and also, to the genotypic characteristics of existent taxa and their adaptative or resilience capacity [46].

4.2. Action Mechanisms of Cyanobacteria with PGPR or PGP Characteristics. Cyanobacteria play a significant role in the maintenance and improvement of soil fertility, by 


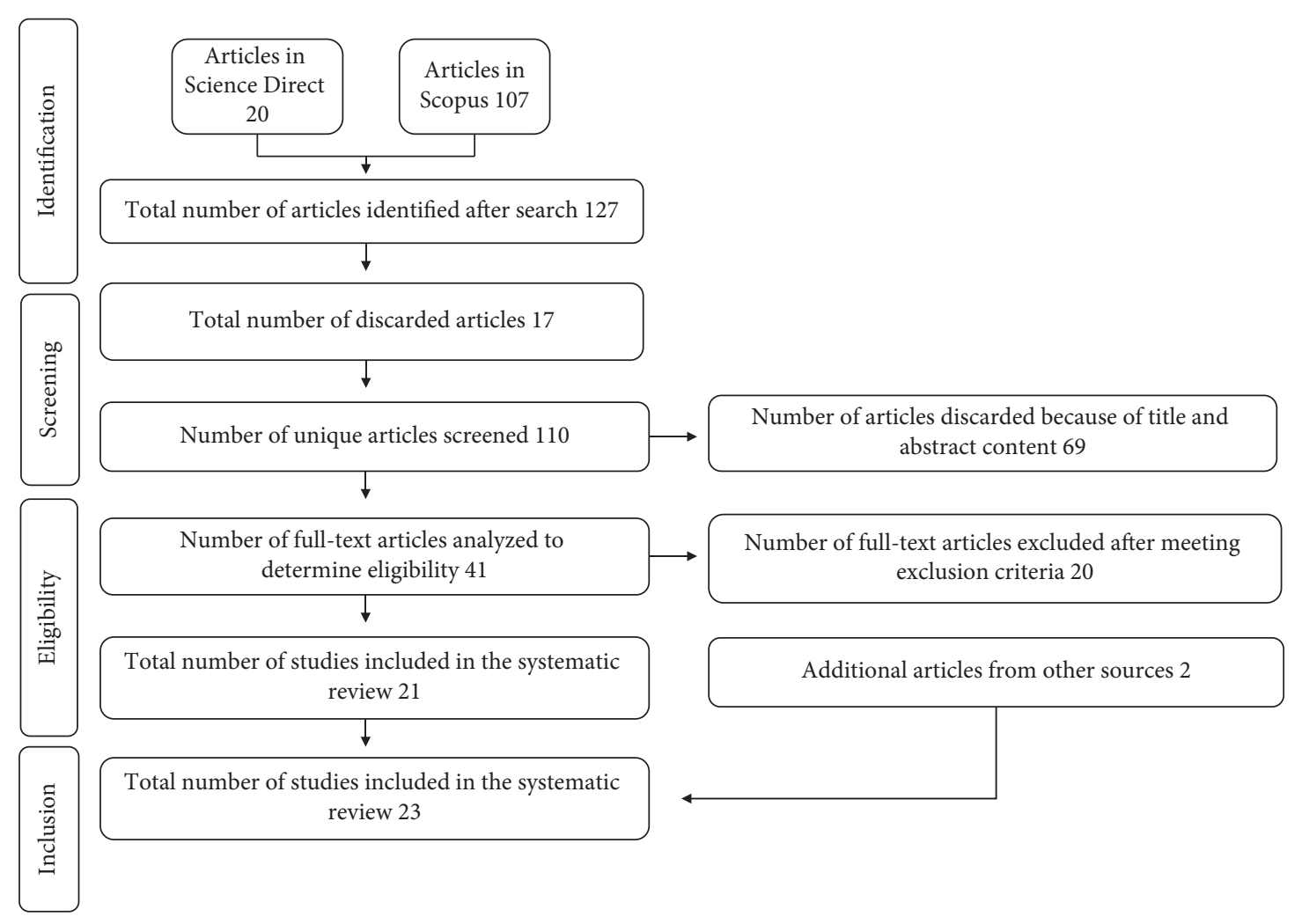

FIGURE 1: Flowchart representing the search protocol used for the systematic review. Source: Urrútia and Bonfill, 2010.

TABLe 1: Articles analyzed in this study

\begin{tabular}{|c|c|c|c|}
\hline Author & Year & Journal & Country \\
\hline Prasanna et al. & $2016 a$ & European Journal of Soil Biology & India \\
\hline Swarnalakshmi et al. & 2013 & European Journal of Soil Biology & India \\
\hline Rana et al. & 2012 & European Journal of Soil Biology & India \\
\hline Nisha et al. & 2018 & International Journal of Environmental Science and Technology & India \\
\hline El-Sheekh et al. & 2018 & Baghdad Science Journal & Egypt \\
\hline Prasanna et al. & 2017 & Archives of Microbiology & India \\
\hline Prasanna et al. & $2016 b$ & Journal of Phytopathology & India \\
\hline Adak et al. & 2016 & Journal of Plant Nutrition & India \\
\hline Verma et al. & 2016 & Israel Journal of Plant Sciences & India \\
\hline Prasanna et al. & 2015 & South African Journal of Plant and Soil & India \\
\hline Tahir et al. & 2015 & PLoS ONE & Pakistan \\
\hline Zayadan et al. & 2014 & Microbiology (Russian Federation) & Russia \\
\hline Shariatmadari et al. & 2013 & Soil Science and Plant Nutrition & Iran \\
\hline Arafa and Abd El-All & 2013 & Journal of Agronomy & Egypt \\
\hline Prasanna et al. & 2013 & Experimental Agriculture & India \\
\hline Prasanna et al. & 2012 & World Journal of Microbiology and Biotechnology & India \\
\hline Manjunath et al. & 2011 & Archives of Agronomy and Soil Science & India \\
\hline Singh et al. & 2011 & Antonie van Leeuwenhoek, International Journal of General and Molecular Microbiology & India \\
\hline Mazhar and Hasnain & 2011 & African Journal of Agricultural Research & Pakistan \\
\hline Osman et al. & 2010 & Biology and Fertility of Soils & Egypt \\
\hline Saadatnia and Riahi & 2009 & Plant, Soil, and Environment & Iran \\
\hline Singha & 2009 & Thesis submitted to the Faculty of Post Graduate School, Indian Agricultural Research Institute ${ }^{1}$ & India \\
\hline Salama & 2015 & Advances in Biochemistry and Biotechnology & Egypt \\
\hline
\end{tabular}

${ }^{1}$ This information source is considered gray literature and refers to a thesis elaborated at the Indian Agricultural Research Institute. Source: own elaboration

improving yields, nutrient uptake, and growth in different types of crops. For that reason, they are considered natural biofertilizers $[17,20]$. In order to cause such effects, cyanobacteria use diverse PGPR mechanisms (Table 3) such as the most often reported $\mathrm{N}_{2}$ fixation [36]. Nevertheless, cyanobacteria are also able to implement other strategies, including increase in soil pores by using filamentous structures and adhesive substances, excretion of 


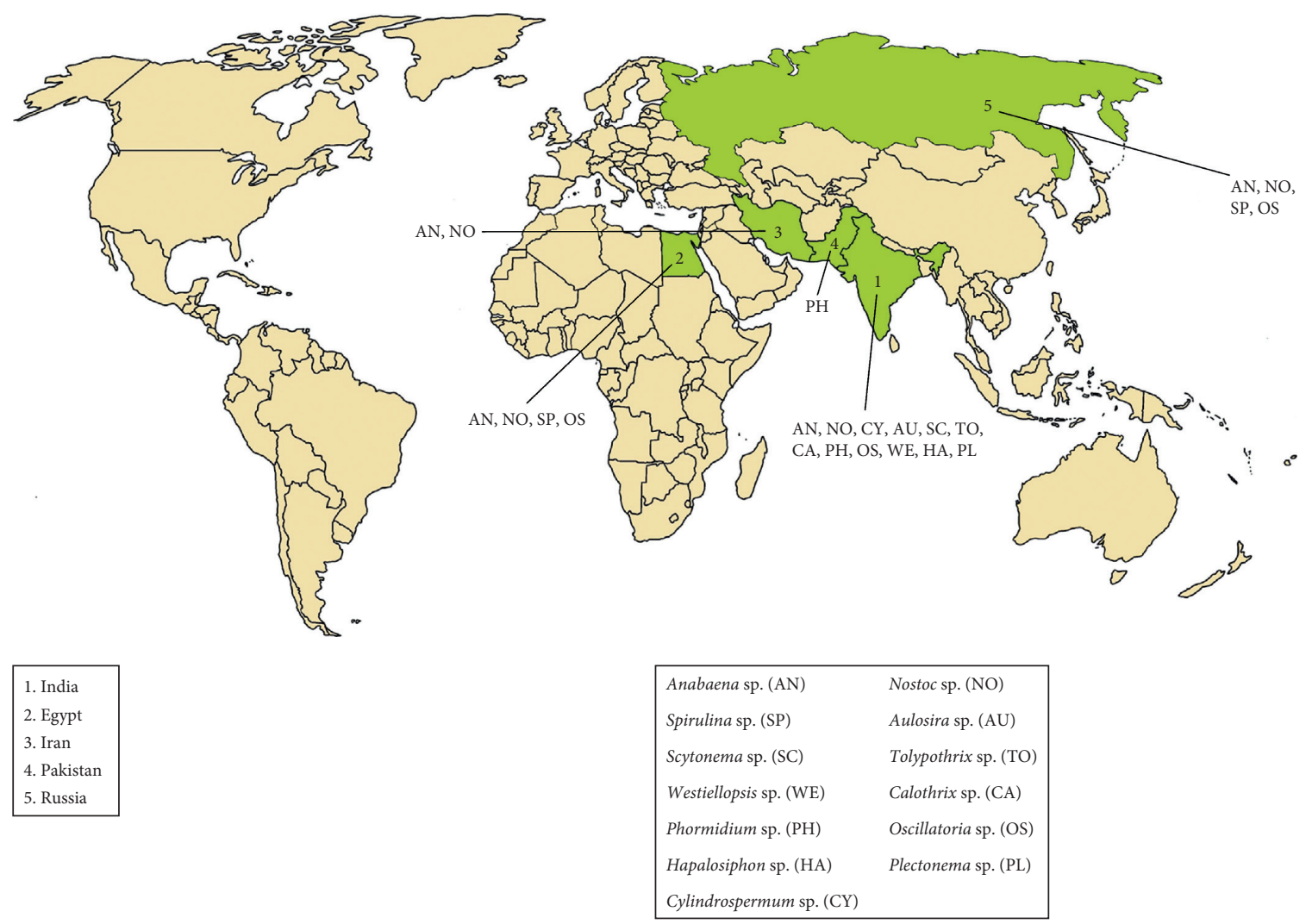

Figure 2: Country of origin of publications found in the systematic review and most reported cyanobacterial genera. Source: own elaboration

TABLE 2: Research objectives

Research objective

To understand and evaluate the PGPR effect of various cyanobacterial strains on wheat and pea crops

To isolate and identify native plant-growth-promoting cyanobacterial strains in wheat and rice crops

To determine the effectiveness of cyanobacteria colonization, their physical, metabolic and enzymatic effects, as well

as their impact as biofertilizers in stressed soils, corn, and rice crops

To identify the most promising combinations of plant growth promoting cyanobacteria for effective nutrient management in rice plants

To improve rice plants efficiency in saline soil and decrease the electrical conductivity of the soil using $\mathrm{N}$-fixing cyanobacteria as biofertilizers

To determine the potential of a consortium of endogenous cyanobacteria and CBBs (cyanobacterial biofilmed fertilizers) for the bioremediation of soil and wheat crops growth under greenhouse conditions

Reference

$[19,20,25,29-31]$.

$[4,32-36]$.

$[17,37-40]$.

$[32,35,41-43]$.

$[32,44]$.

$[18,31,45]$

Source: own elaboration

growth promoting substances such as hormones (auxins and gibberellins), vitamins and amino acids, increased capacity of soils to retain water, increased nutrient availability after their death, decreased salinity, prevention of weeds growth, and increased amount of soluble phosphate in soils through the excretion of organic acids and extracellular polysaccharides, among others $[4,17,36]$. Some cyanobacteria can secrete hydrogen cyanide, which functions as an antibacterial and antifungal substance, allowing the biocontrol of phytopathogens [41]. It should be noted that the quantity and quality of the excreted compounds vary according to the cyanobacterial species, their growth phase, and the environmental conditions to which they are exposed [4].
Cyanobacteria are major elements of biogeochemical cycles, specifically, carbon and nitrogen cycles [18]. Moreover, there is evidence of the capacity of free-living cyanobacteria such as Synechococcus sp., Anabaena sp., Chlorogloeopsis sp., and Nostoc sp. to establish symbiotic associations with a wide range of eukaryotic organisms (Panax, Medicago, Nicotiana or wheat, corn, bean, sugar beet, and rice crops), which constitutes an effective mechanism to promote plant growth [18]. There is also proof of the ability of cyanobacteria to excrete indole-3acetic acid (IAA), amino acids, and other compounds to the environment, which can enter the root cortex, stimulating the growth of soil microbial populations [25]. 


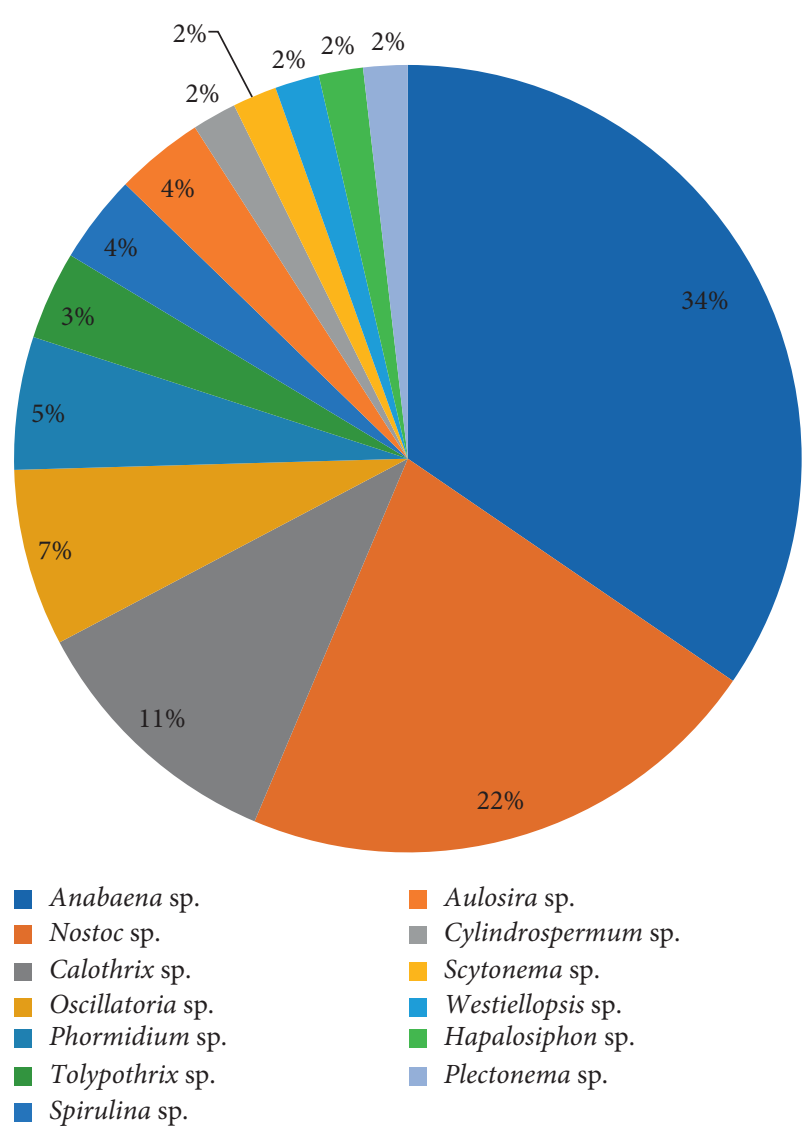

FIgURE 3: Most recurrent cyanobacteria genera in the articles reviewed. Source: own elaboration

A study conducted by Swarnalakshmi et al. in 2013 analyzes the effect of nitrogen-fixing cyanobacteria and phosphate solubilizers in wheat seeds under controlled conditions. When microbiological parameters, soil chlorophyll and nitrogenase activity, were estimated at 4 to 14 days after sowing, an increase in soil chlorophyll was found, due to the establishment of cyanobacterial biofilms. The treatments with the highest chlorophyll content and the highest acetylene reducing activity involved the genus Anabaena sp; Anabaena sp. inoculants in soil recorded a $57.42 \%$ increase in available nitrogen, compared with the controls used in the study.

Adak et al. [32], Prasanna et al. [38], Salama [35], and Verma et al. [31] also reported nitrogen fixation by cyanobacteria as a PGPR characteristic in different crops. On the other hand, in the study conducted by Nisha et al. in 2018, the biofertilizers used were composed of two isolated strains of Nostoc sp. and led to the increase of key nutrients such as total Kjeldahl nitrogen (TKN) (7-16\%), total organic carbon (TOC) (12\%) and available phosphorus (17\%) in saline soil. Regarding the mechanism of phosphate solubilization, it was reported that when this element is assimilated by cells during growth and then released, it decomposes as soluble organic phosphate compounds and is subsequently mineralized to orthophosphate, causing soil available phosphate to increase. Such is the reason for the significant role cyanobacteria application plays in inorganic phosphate mobilization by producing extracellular phosphatases and excreting organic acids. The study also showed that the treatment with cyanobacteria significantly increased carbon mineralization in soil. Finally, soil treated with cyanobacteria also showed an effect on nitrogen mineralization, where there was an increase of 22 to $60 \%$ in $\mathrm{NH}_{4} \pm \mathrm{N}$. The heterocystic cyanobacteria used were able to fix $\mathrm{N}_{2}$ by increasing TKN [45].

Singh et al. [40] evaluated the effect of the colonization of several strains of cyanobacteria in rice crop, at physical, metabolic, and enzymatic levels. This study presents the mechanisms of phytohormone production and bioactive compound excretion. The plants inoculated with Plectonema boryanum after 15 days showed a maximum plant and root length of $17.6 \mathrm{~cm}$ and $7.3 \mathrm{~cm}$, respectively, a plant weight of $2.18 \mathrm{~g}$, and after 30 days, $24.1 \mathrm{~cm}, 8.6 \mathrm{~cm}$, and $3.1 \mathrm{~g}$, respectively, compared with that of the control without cyanobacteria. Rice leaves showed a maximum accumulation of total phenol after the inoculation with Anabaena oryzae 30 days after sowing. The production of phenolic acids and flavonoids, involved in plant/microorganism interactions and in the promotion of the root being colonized by $\mathrm{mi}$ croorganisms, was also reported. Finally, there was evidence of various metabolites in the rhizosphere enhancing the growth of other cyanobacteria and higher plants. All things considered, the cumulative effect of metabolites such as phenolic compounds, flavonoids, and phytohormones like IAA and abscisic acid is thus proven; these, together with amino acids such as aspartic acid, glutamic acid, proline, valine, glycine, and alanine, produced and released by cyanobacterial inoculants in the plant rhizosphere, are directly responsible for the PGPR effect or PGP characteristics $[25,29,31,32]$.

\subsection{Effects of Cyanobacteria Used as PGPR Microorgan-} isms or Those Having PGP Characteristics. Soil-plant-microorganism interactions are complex and have the primary role in both plant health and productivity [42]. Many studies have suggested that plants protect themselves from damage originated in oxidative stress as well as from pathogens and adverse environmental conditions. The colonization of PGPR microorganisms, such as cyanobacteria in the root, is thus one of the main defense mechanisms that allow them to fight such types of problems [40]. Some of the most frequently reported effects of cyanobacteria as PGPRs are the improvement in plant growth and crop yields, reflected in the length of roots, leaves, and plant structures. Besides, it has been found that using cyanobacteria as biofertilizers reduces the use of nitrogen fertilizers by up to 50\% [29]. The cyanobacteria is considered important in carbon, nitrogen, and oxygen cycles, since they are responsible for the production of $30 \%$ of the oxygen on the planet every year [45]. These microorganisms can also produce biocontrol agents, useful for the treatment of phytopathogenic microorganisms [37].

Nowadays, many of these effects continue to be reported by a number of authors. In a study carried out in Egypt, after applying a treatment with Nostoc sp., Anabaena sp., and 
TABle 3: Cyanobacterial genera classified according to their PGPR action mechanisms o PGP characteristics

\begin{tabular}{|c|c|c|}
\hline Mechanism & Cyanobacterial genera & References \\
\hline $\mathrm{N}_{2}$ fixation & $\begin{array}{c}\text { Nostoc sp., Anabaena sp., Cylindrospermum sp., Phormidium sp., } \\
\text { Oscillatoria sp. }\end{array}$ & {$[4,18,19,29-38,44,45]$} \\
\hline $\begin{array}{l}\text { Phosphate } \\
\text { solubilization }\end{array}$ & Anabaena sp., Calothrix sp., Nostoc sp., Oscillatoria sp., Phormidium sp. & {$[18,20,29,31,33-35,37,38,42,45]$.} \\
\hline $\begin{array}{l}\text { Phytohormone } \\
\text { production }\end{array}$ & $\begin{array}{c}\text { Anabaena sp., Calothrix sp., Nostoc sp., Phormidium sp., Hapalosiphon } \\
\text { sp., Aulosira sp., Tolypothrix sp., Oscillatoria sp., Plectonema sp. }\end{array}$ & {$[18-20,25,29,33,40,42]$.} \\
\hline $\begin{array}{l}\text { Bioactive compound } \\
\text { excretion }\end{array}$ & $\begin{array}{l}\text { Anabaena sp., Calothrix sp., Nostoc sp., Phormidium sp., Hapalosiphon } \\
\text { sp., Aulosira sp., Tolypothrix sp., Oscillatoria sp., and Plectonema sp. }\end{array}$ & {$[20,29,31,33,39,40,43,45]$} \\
\hline Symbiotic associations & $\begin{array}{l}\text { Nostoc sp., Anabaena sp., Cylindrospermum sp., Phormidium sp., } \\
\text { Synechococcus sp.,Chlorogloeopsis sp., Spirulina sp. }\end{array}$ & {$[4,18,37,41]$} \\
\hline
\end{tabular}

Source: own elaboration

Calothrix sp. cyanobacteria, Salama [35] reported increased height of rice plants with maximum values of $86.92 \mathrm{~cm}$ and $83.75 \mathrm{~cm}$, compared with that of the controls, where values of $70.21 \mathrm{~cm}$ were obtained. Additionally, findings indicated that with the individual or combined inoculation of these cyanobacteria, both the crop yield and 1000 grain weight of rice plants significantly increased in comparison to treatments without inoculation. The influence of treatments with cyanobacteria was notorious in another study, carried out by Saadatnia and Riahi in 2009. Cyanobacteria were used in a rice crop in Iran, where germination was observed 2 days after sowing, and a $3 \mathrm{~cm}$ root length was also obtained, whereas the seeds in the control group germinated 5 days after sowing, with a $0.5 \mathrm{~cm}$ root length. The same study makes reference to previous research reporting a $69 \%$ increase in root length, $137.5 \%$ in plant fresh weight, $20 \%$ in plant dry weight, $28 \%$ in soil moisture, and $9.8 \%$ in soil porosity. The authors like Manjunath et al. [25], Osman et al. [29], and Shariatmadari et al. [19] report the production of phytohormones like IAA, stimulating the growth of crops in which the treatments with cyanobacteria were applied.

\subsection{Types of Crops Where Cyanobacteria Biofertilizers Have} Been Tested. Cropping systems of rice and wheat, cereals of high demand in Asia and much of the world, occupy about 24 million hectares of cultivated land only in the Asian continent. It is precisely in this type of crops where the effect of microorganisms such as cyanobacteria has been studied in order to mitigate the decrease in yields and improve their sustainability $[4,17]$. The potential of this type of microorganisms to increase nutrient availability in staple food crops of corn, bean, and cassava, as well as cotton crops, has also been studied [20, 29, 30, 38].

At present, the use of cyanobacteria as biofertilizers continues to be widely studied mainly in rice and wheat crops $[17,20,25,36]$. However, the authors like Osman et al. [29], Prasanna et al. [37, 39], Shariatmadari et al. [19], and Swarnalakshmi et al. [19] also report in their studies the positive impact of cyanobacteria on pea, corn, bean, sugar beet, pumpkin, cucumber, potato, and tomato crops, pointing at the growing expansion of the use of biofertilizers based on cyanobacteria to improve yields of all kinds of crops.

\section{Conclusions}

Most studies on the use of cyanobacteria as biofertilizers and their mechanisms to promote plant growth in diverse types of crops come from the Asian continent and from part of Africa, which may be due to the largest cereal-producing countries in the world being located there, with extensive fields of corn and wheat, among other products. Although there were no studies conducted in the American continent, more specifically, in Latin America, the use of cyanobacteria as PGP microorganisms is shown as a promising practice to increase yields, soil quality, and crops typical in the region. This practice would benefit from the tropical weather of South American countries since it would substantially promote the proliferation of several cyanobacterial genera with PGP characteristics.

This systematic review evidenced various beneficial effects that cyanobacteria have on plants, such as a significant increase in plant and root length and a reduction in the use of chemical fertilizers in crops, with an ensuing progressive reduction of environmental pollution and production costs in agriculture.

The use of cyanobacteria as biofertilizers may be a promising strategy because these microorganisms show a great adaptability to environmental conditions; additionally, they contribute an important volume of biomass to soil, even after their death. They may also help in the regulation of biological functions in other microorganisms that are beneficial to soil, as many of the articles that we analyzed have shown. Thus, cyanobacteria abundance and diversity may change the soil's conditions, the same as soil conditions may change cyanobacteria populations. This is an important reason to promote these types of studies, which may help in finding trends or differences in further studies that can guide decision taking.

\section{Data Availability}

The research articles used to support the findings of this study are available from the corresponding author upon request at the e-mail: leonardo.rios@udea.edu.co.

\section{Conflicts of Interest}

The authors have no conflicts of interest to disclose. 


\section{Acknowledgments}

This work was supported by the Universidad de Antioquia.

\section{References}

[1] S. Savci, "Investigation of effect of chemical fertilizers on environment," APCBEE Procedia, vol. 1, pp. 287-292, 2012.

[2] D. Zaring, "Agriculture, nonpoint source pollution, and regulatory control: the clean water act's bleak present and future," HELR Harvard Environ Law Rev, vol. 20, p. 515, 1996.

[3] D.. Chittora, M.. Meena, T.. Barupal, P.. Swapnil, and K. Sharma, "Cyanobacteria as a source of biofertilizers for sustainable agricultura," BB Reports, vol. 22, p. 100737, 2020.

[4] A. Singha, "Diversity of cyanobacteria in organic farming field under ricewheat cropping system," Doctoral Thesis, Indian Agricultural Research Institute, New Delhi, India, 2009.

[5] IPCC, "Climate change 2007: mitigation,"“Climate change 2007: mitigation," in Contribution of Working Group III to the Fourth Assessment Report of the IPCC, B. Metz, O. R. Davidson, P. R. Bosch, R. Dave, and L. A. Meyer, Eds., Cambridge University Press, Cambridge, UK, 2007.

[6] A. Popp, H. Lotze-Campen, and B. Bodirsky, "Food consumption, diet shifts and associated non- $\mathrm{CO}_{2}$ greenhouse gases from agricultural production," Global Environmental Change, vol. 20, no. 3, pp. 451-462, 2010.

[7] M. Qiu, R. Zhang, C. Xue et al., “Application of bio-organic fertilizer can control Fusarium wilt of cucumber plants by regulating microbial community of rhizosphere soil," Biology and Fertility of Soils, vol. 48, pp. 807-816, 2012.

[8] N. Chuan-chuan, G. Peng-dong, W. Bing-qing, L. Wei-peng, J. Ni-hao, and C. Kun-zheng, "Impacts of chemical fertilizer reduction and organic amendments supplementation on soil nutrient, enzyme activity and heavy metal content," Journal of Integrative Agriculture, vol. 16, no. 8, pp. 1819-1831, 2017.

[9] P. C. Nagajyoti, K. D. Lee, and T. V. M. Sreekanth, "Heavy metals, occurrence and toxicity for plants: a review," Environmental Chemistry Letters, vol. 8, no. 3, pp. 199-216, 2010.

[10] USEPA, Priority Pollutant List, USEPA (United States Environment Protection Agency), Washington, DC, USA, 2014, https://www.epa.gov/eg/toxic-and-priority-pollutants-underclean-water-act.

[11] A. Bramki, M. Ramdhane, and F. Benrachi, "Natural radioelement concentrations in fertilizers and the soil of the Mila region of Algeria," Journal of Radiation Research and Applied Sciences, vol. 11, no. 1, pp. 49-55, 2018.

[12] M. A. Mathur, M. F. Dias, and M. P. Mathur, "Importance of green technology in fertilizer quality improvement," Procedia Engineering, vol. 138, pp. 308-313, 2016.

[13] H. Yin, W. Zhao, T. Li, X. Cheng, and Q. Liu, "Balancing straw returning and chemical fertilizers in China: role of straw nutrient resources," Renewable and Sustainable Energy Reviews, vol. 81, pp. 2695-2702, 2018.

[14] D. Kantachote, T. Nunkaew, T. Kantha, and S. Chaiprapat, "Biofertilizers from Rhodopseudomonas palustris strains to enhance rice yields and reduce methane emissions," Applied Soil Ecology, vol. 100, pp. 154-161, 2016.

[15] A. Barragan-Ocaña, M. del-Valle-Rivera, and C. del, "Rural development and environmental protection through the use of biofertilizers in agriculture: an alternative for underdeveloped countries?" Technology in Society, vol. 46, pp. 90-99, 2016.

[16] E. Montesinos, A. Bonaterra, E. Badosa et al., "Plant-microbe interactions and the new biotechnological methods of plant disease control," International Microbiology, vol. 5, no. 4, pp. 169-175, 2002.

[17] H. Saadatnia and H. Riahi, "Cyanobacteria from paddy fields in Iran as a biofertilizer in rice plants," Plant Soil Environment, vol. 55, pp. 207-212, 2009.

[18] K. Swarnalakshmi, R. Prasanna, A. Kumar et al., "Evaluating the influence of novel cyanobacterial biofilmed biofertilizers on soil fertility and plant nutrition in wheat," European Journal of Soil Biology, vol. 55, pp. 107-116, 2013.

[19] Z. Shariatmadari, H. Riahi, M. Seyed Hashtroudi, A. Ghassempour, and Z. Aghashariatmadary, "Plant growth promoting cyanobacteria and their distribution in terrestrial habitats of Iran," Journal of Soil Science and Plant Nutrition, vol. 59, no. 4, pp. 535-547, 2013.

[20] A. Rana, M. Joshi, R. Prasanna, Y. S. Shivay, and L. Nain, "Biofortification of wheat through inoculation of plant growth promoting rhizobacteria and cyanobacteria," European Journal of Soil Biology, vol. 50, pp. 118-126, 2012.

[21] T. L. Pham, L. T. T. Nguyen, T. A. Duong et al., "Diversity and bioactivities of nostocacean cyanobacteria isolated from paddy soil in Vietnam," Systematic and Applied Microbiology, vol. 40, pp. 470-481, 2017.

[22] R. Wang, B. Peng, and K. Huang, "The research progress of $\mathrm{CO}_{2}$ sequestration by algal bio-fertilizer in China," Journal of CO2 Utilization, vol. 11, pp. 67-70, 2015.

[23] V. Gupta, S. K. Ratha, A. Sood, V. Chaudhary, and R. Prasanna, "New insights into the biodiversity and applications of cyanobacteria (blue-green algae)-Prospects and challenges," Algal Research, vol. 2, no. 2, pp. 79-97, 2013.

[24] N. Schuergers, C. W. Mullineaux, and A. Wilde, "Cyanobacteria in motion," Current Opinion in Plant Biology, vol. 37, pp. 109-115, 2017.

[25] M. Manjunath, R. Prasanna, P. Sharma, L. Nain, and R. Singh, "Developing PGPR consortia using novel genera Providencia and Alcaligenes along with cyanobacteria for wheat," Archives of Agronomy and Soil Science, vol. 57, no. 8, pp. 873-887, 2011.

[26] S. Gkelis and N. Zaoutsos, "Cyanotoxin occurrence and potentially toxin producing cyanobacteria in freshwaters of Greece: a multi-disciplinary approach," Toxicon, vol. 78, pp. 1-9, 2014.

[27] K. A. Kormas, S. Gkelis, E. Vardaka, and M. Moustaka-Gouni, "Morphological and molecular analysis of bloom-forming Cyanobacteria in two eutrophic, shallow Mediterranean lakes," Limnologica, vol. 41, no. 3, pp. 167-173, 2011.

[28] G. Urrútia and X. Bonfill, "Declaración PRISMA: una propuesta para mejorar la publicación de revisiones sistemáticas y metaanálisis," Medicina Clínica, vol. 135, pp. 507-511, 2010.

[29] M. E. H. Osman, M. M. El-Sheekh, A. H. El-Naggar, and S. F. Gheda, "Effect of two species of cyanobacteria as biofertilizers on some metabolic activities, growth, and yield of pea plant," Biology and Fertility of Soils, vol. 46, no. 8, pp. 861-875, 2010.

[30] M. Tahir, M. S. Mirza, S. Hameed, M. R. Dimitrov, and H. Smidt, "Cultivation-based and molecular assessment of bacterial diversity in the rhizosheath of wheat under different crop rotations," PloS One, vol. 10, no. 6, 2015.

[31] S. Verma, A. Adak, R. Prasanna et al., "Microbial priming elicits improved plant growth promotion and nutrient uptake in pea," Israel Journal of Plant Sciences, vol. 63, no. 3, pp. 191-207, 2016.

[32] A. Adak, R. Prasanna, S. Babu et al., "Micronutrient enrichment mediated by plant-microbe interactions and rice cultivation practices," Journal of Plant Nutrition and Soil Science, vol. 39, no. 9, pp. 1216-1232, 2016. 
[33] S. Mazhar and S. Hasnain, "Screening of native plant growth promoting cyanobacteria and their impact on Triticum aestivum var. Uqab 2000 growth," African Journal of Agricultural Research, vol. 6, no. 17, pp. 3988-3993, 2011.

[34] R. Prasanna, S. Babu, A. Rana et al., "Evaluating the establishment and agronomic proficiency of cyanobacterial consortia as organic options in wheat-rice cropping sequence," Journal of Experimental Agriculture International, vol. 49, no. 3, pp. 416-434, 2013.

[35] A. Salama, "Response of rice plants to inoculation with indigenous strains of cyanobacterial along with different levels of inorganic n-fertilizers," Advances in Biochemical Engineering/Biotechnology, vol. 1, pp. 1-14, 2015.

[36] B. K. Zayadan, D. N. Matorin, G. B. Baimakhanova, K. Bolathan, G. D. Oraz, and A. K. Sadanov, "Promising microbial consortia for producing biofertilizers for rice fields," Microbiology, vol. 83, no. 4, pp. 391-397, 2014.

[37] R. Prasanna, F. Hossain, S. Babu et al., "Prospecting cyanobacterial formulations as plant-growth-promoting agents for maize hybrids," South African Journal of Plant and Soil, vol. 20, pp. 199-207, 2015.

[38] R. Prasanna, B. Ramakrishnan, K. Ranjan et al., "Microbial inoculants with multifaceted traits suppress rhizoctonia populations and promote plant growth in cotton," Journal of Phytopathology, vol. 164, pp. 1030-1042, 2016 b.

[39] R. Prasanna, B. Ramakrishnan, K. Simranjit et al., "Cyanobacterial and rhizobial inoculation modulates the plant physiological attributes and nodule microbial communities of chickpea," Archives of Microbiology, vol. 199, no. 9, pp. 1311-1323, 2017.

[40] D. P. Singh, R. Prabha, M. S. Yandigeri, and D. K. Arora, "Cyanobacteria-mediated phenylpropanoids and phytohormones in rice enhance plant growth and stress tolerance," Antonie Van Leeuwenhoek, vol. 100, no. 4, pp. 557-568, 2011.

[41] A. S. Arafa and A. M. A. Abd El-All, "Evaluation of the technological properties of the bio-organic colored cotton," Journal of Agronomy, vol. 12, no. 2, pp. 78-85, 2013, https:// scialert.net/fulltext/?doi=ja.2013.78.85.

[42] R. Prasanna, M. Joshi, A. Rana, Y. S. Shivay, and L. Nain, "Influence of co-inoculation of bacteria-cyanobacteria on crop yield and C-N sequestration in soil under rice crop," World Journal of Microbiology and Biotechnology, vol. 28, no. 3, pp. 1223-1235, 2012.

[43] R. Prasanna, A. Kanchan, B. Ramakrishnan et al., "Cyanobacteria-based bioinoculants influence growth and yields by modulating the microbial communities favourably in the rhizospheres of maize hybrids," European Journal of Soil Biology, vol. 75, pp. 15-23, 2016a.

[44] M. M. El -Sheekh, M. A. Zayed, F. K. A. Elmossel, and R. S. A. Hassan, "Effect of cyanobacteria isolates on rice seeds germination in saline soil," Baghdad Science Journal, vol. 15, no. 1, pp. 16-21, 2018.

[45] R. Nisha, B. Kiran, A. Kaushik, and C. P. Kaushik, "Bioremediation of salt affected soils using cyanobacteria in terms of physical structure, nutrient status and microbial activity," International Journal of Environmental Science and Technology, vol. 15, no. 3, pp. 571-580, 2018.

[46] M. Guenther, M. Araújo, M. Flores-Montes, E. GonzalezRodriguez, and S. Neumann-Leitão, "Eutrophication effects on phytoplankton size-fractioned biomass and production at a tropical estuary," Marine Pollution Bulletin, vol. 91, no. 2, pp. 537-547, 2015 